\title{
DETERMINAÇÃO DO FATOR DE COBERTURA DO MELÃO CULTIVADO SOB DIFERENTES LÂMINAS E SALINIDADES DA ÁGUA DE IRRIGAÇÃO' ${ }^{1}$
}

\author{
Indalécio Dutra ${ }^{2}$, José Francismar de Medeiros ${ }^{3}$, Francisco de Queiroz Porto Filho ${ }^{4}$ \& \\ Maristélio da Cruz Costa ${ }^{5}$
}

\section{RESUMO}

Dois experimentos foram conduzidos com objetivo de se comparar metodologias de determinação do coeficiente de cobertura do solo pelo melão, quando submetido a condições diferenciadas de lâminas e nível de salinidade da água, em Mossoró, RN. O delineamento experimental adotado foi o de blocos ao acaso, no arranjo fatorial $2 \times 2 \times 6$. Foram testados dois métodos (Stocking e régua), dois níveis de salinidade da água de irrigação $\left(0,55\right.$ e 2,65 $\left.\mathrm{dS} \mathrm{m}^{-1}\right)$ e seis lâminas $(0,55,0,70,0,85,1,00$, 1,15 e 1,30 da ETm). Os métodos de medida do fator de cobertura do solo mostraram-se eficientes, detectando-se, em ambos, diferenças significativas entre os efeitos da qualidade da água e da lâmina de irrigação no desenvolvimento do melão. Os resultados obtidos pelo método da régua diferiram do método de Stocking apenas nas fases inicial e de crescimento do melão.

Palavras-chave: déficit hídrico, coeficiente de cobertura, irrigação localizada

\section{DETERMINATION OF THE SOIL COVER FACTOR FOR MELON GROWN UNDER DIFFERENT DEPTHS AND IRRIGATION WATER SALINITIES}

\begin{abstract}
Two experiments were carried out with the objective of comparing methodologies for determination of the soil cover factor of melon when submitted to different conditions of water depths and salinity, in Mossoro, RN. The experimental design was of completely randomized blocks in a $2 \times 2 \times 6$ factorial scheme. Two methods were tested (Stocking's and ruler), two salinity levels $\left(0.55\right.$ and $\left.2.65 \mathrm{dS} \mathrm{m}^{-1}\right)$ and six water depths $(0.55,0.70,0.85,1.00,1.15$ and 1.30 of the ETc). Both methods of measurement were efficient, with significant effects for both irrigation water depths and salinity in the melon crop being observed. The results obtained by the ruler method differed from Stocking's method in the melon only during the initial and rapid growth stages.
\end{abstract}

Key words: water deficit, cover coefficient, drip irrigation

Recebido em 08/09/1999, Protocolo 101/99

${ }^{1}$ Trabalho de conclusão do curso de Especialização em Irrigação e Drenagem do primeiro autor, na ESAM

${ }^{2}$ Eng. Agr., Mestrando da UFC, Av. da Universidade, 3264, CEP 60020 - 181, Fortaleza, CE. Fone: (0xx85) 2814843. E-mail: indutra35@hotmail.com

${ }^{3}$ Eng. Agr., Doutor, Departamento de Eng. Agrícola, ESAM, CEP 59625 - 900, Mossoró, RN. Fax: (0xx84) 3122499. E-mail: jfmedeir@esam.br

${ }^{4}$ Doutorando na UFPB, Prof. Adj., M. Sc., Departamento de Eng. Agrícola, ESAM, CEP 59625 - 900, Mossoró, RN. E-mail: portofilho@esam.br

${ }^{5}$ Eng. Agr., Doutor em Irrigação e Drenagem - UFRN, CEP 59000 - 000, Natal, RN. E-mail: maristélio@esam.br 


\section{INTRODUÇÃO}

O melão é uma das espécies olerícolas de maior expansão na região Nordeste do Brasil. O cultivo racional é desenvolvido em grandes proporções nos Estados do Rio Grande do Norte, Ceará, Pernambuco e Bahia que, juntos, contribuem com mais de $90 \%$ da produção nacional e, atualmente, vem-se destacando como uma das principais frutas exportadas e consumidas no país (Aragão Júnior et al.,1991).

O nível de qualidade dos frutos exigidos na comercialização é alta, principalmente pelo mercado externo, e isto faz com que os produtores necessitem de tecnologias avançadas para a sua produção, através do uso de insumos modernos e assistência técnica especializada.

A irrigação por gotejamento tem sido a mais eficiente para aumentar a produtividade do meloeiro (Abreu et al., 1978) mas sua eficiência depende do conhecimento e do estudo de vários fatores, entre eles o manejo da irrigação, associado ao manejo do sistema solo-planta-atmosfera.

A quantificação da água evaporada pelo sistema solo-plantaatmosfera é de grande importância, pois se trata de um parâmetro de referência quando da realização do balanço hídrico, dimensionamento e manejo de sistema de irrigação; quanto ao dimensionamento e manejo do sistema, o conhecimento da necessidade hídrica é de fundamental significância; assim, torna-se imprescindível o estudo de técnicas que visem a uma determinação melhor desta variável.

A forma de se determinar as necessidades hídricas das culturas, quando se irriga toda a superfície do solo, é diferente do caso de se irrigar apenas parte dela, que, geralmente, será em função da área coberta pela planta; deste modo, a demanda de água devido à evaporação do solo será mínima e a evapotranspiração da cultura praticamente se restringe à transpiração das plantas (Allen et al., 1996).

Segundo Olitta (1986) nas primeiras tentativas para a determinação das necessidades hídricas em projetos de irrigação localizada, um sistema por gotejamento, procurou-se uma redução na área de irrigação através de um coeficiente, de modo a compensar a diferença, já que somente parte da superfície do solo é molhada. Um dos processos citados pelo autor refere-se ao método baseado no coeficiente de cobertura do solo, em que o consumo de água pela planta é estimado a partir da quantidade de solo coberto pela cultura, o qual indica o raio de ação do sistema radicular da planta.

Segundo Gomes (1994) no caso particular da irrigação localizada, para se obter a evapotranspiração máxima da cultura, deve-se aplicar um coeficiente de redução $(\mathrm{Kr})$ ao valor da evapotranspiração; esse coeficiente de redução pode ser obtido em função do coeficiente de cobertura do solo.

Pizarro (1990) relata a necessidade de se corrigir a evapotranspiração máxima das culturas, quando se trata de irrigação localizada de alta freqüência e que esta correção é realizada através do coeficiente de redução, denominado efeito de localização. O processo mais rápido de se determinar este efeito baseia-se na avaliação da fração do solo sombreado pela parte aérea da planta. Mesma recomendação é enfatizada por Keller \& Bliesner (1990) e Hernández Abreu (1979).

O coeficiente de cobertura ou fator de cobertura, expresso em porcentagem, é definido como a razão entre a área coberta pela cultura e a área ocupada por seu espaçamento. Para árvores frutíferas de grande espaçamento, tal coeficiente pode ser obtido diretamente através de medições no campo, e para culturas com espaçamento reduzido, cuja vegetação cobre toda a superfície do solo, adota-se o valor máximo para o dimensionamento de sistema de irrigação, enquanto para o manejo de irrigação se deve considerar o aumento progressivo do valor do fator de cobertura, de acordo com o desenvolvimento vegetativo da cultura (Keller \& Bliesner, 1990; Pizarro, 1990).

Bedum et al. (1993) pesquisaram a produtividade do melão sob diferentes lâminas e estimaram a percentagem de solo coberto pela cultura através de medidas de comprimento de ramos, transversalmente, em relação à linha de semeadura, dividida pelo espaçamento da cultura.

Hernandez (1995) em pesquisa sobre o déficit hídrico na cultura do melão utilizou, no cálculo da evapotranspiração da cultura, o fator de cobertura do solo, através de medições da rama com régua milimetrada.

Uma metodologia baseada em observações das diferentes fases fenológicas da planta, através de uma peça de madeira (Figura 1) foi proposta por Stocking (1985). Este método consiste em acompanhar o crescimento dos ramos através de observações em várias posições diferentes na parcela. Bezerra (1995) utilizou esta metodologia para determinar a cobertura do solo pela cultura do melão e verificou que houve maior crescimento no período de 17 a 37 dias e que aos 52 dias as plantas cobriam 100\% da área.

Em vista do exposto e se considerando a importância do fator de cobertura para o manejo da irrigação localizada, este trabalho teve como objetivo estudar metodologias usadas na determinação do coeficiente de cobertura do solo pelas plantas de melão, quando irrigadas por gotejamento e submetidas a diferentes lâminas de irrigação e salinidade de água.

\section{MATERIAL E MÉTODOS}

Os experimentos foram conduzidos na Fazenda São João Ltda, localizada na rodovia RN 015, km 04, município de Mossoró, RN. O primeiro experimento foi conduzido no período de 22 de agosto a 30 de outubro de 1998 e o segundo de 10 de novembro de 1998 a 18 de janeiro de 1999 . O local possui clima BSWh', conforme a classificação de Köppen, altitude de $18 \mathrm{~m}$ com $5^{\circ} 11^{\prime} \mathrm{S}$ de latitude e $37^{\circ} 20^{\prime} \mathrm{W}$ de longitude. Durante os ciclos a temperatura e umidade relativa média foram de $28,7^{\circ} \mathrm{Ce}$ $60,6 \%$ e $28,8^{\circ} \mathrm{C}$ e $66,9 \%$, respectivamente.

$\mathrm{O}$ solo da área foi classificado como Podzólico VermelhoAmarelo Eutrófico latossólico com textura franco-argilo-arenoso, de relevo plano a suave ondulado. As análises química e física do solo são apresentadas na Tabela 1.

Tabela 1. Resultado das análises química e física do solo onde foi instalado o experimento, antes do plantio

\begin{tabular}{|c|c|c|c|}
\hline \multirow[t]{2}{*}{ Parâmetros } & \multirow[t]{2}{*}{ Unidade } & \multicolumn{2}{|c|}{ Profundidade $(\mathrm{cm})$} \\
\hline & & $0-20$ & $20-40$ \\
\hline $\mathrm{Ca}^{2+}$ & $\mathrm{cmol}_{\mathrm{c}} \mathrm{kg}^{-1}$ & 3,6 & 3,5 \\
\hline $\mathrm{Mg}^{2+}$ & $\mathrm{cmol}_{\mathrm{c}} \mathrm{kg}^{-1}$ & 1,5 & 1,6 \\
\hline $\mathrm{K}^{+}$ & $\mathrm{cmol}_{\mathrm{c}} \mathrm{kg}^{-1}$ & 0,40 & 0,40 \\
\hline $\mathrm{Na}^{+}$ & $\mathrm{cmol}_{\mathrm{c}} \mathrm{kg}^{-1}$ & 0,21 & 0,20 \\
\hline $\mathrm{Al}^{3+}$ & $\mathrm{cmol}_{\mathrm{c}} \mathrm{kg}^{-1}$ & 0,0 & 0,0 \\
\hline $\mathrm{P}$ & $\mathrm{mg} \mathrm{kg}^{-1}$ & 12 & 8 \\
\hline $\mathrm{CE}_{\mathrm{es}}$ & $\mathrm{dS} \mathrm{m} \mathrm{m}^{-1}$ & 0,7 & 0,6 \\
\hline $\mathrm{pH}_{\mathrm{H}_{2} \mathrm{O}}(1: 2,5)$ & - & 6,7 & 6,5 \\
\hline Argila & $\mathrm{g} \mathrm{kg}^{-1}$ & 177 & 241 \\
\hline Silte & $\mathrm{g} \mathrm{kg}^{-1}$ & 42 & 26 \\
\hline Areia & $\mathrm{g} \mathrm{kg}^{-1}$ & 781 & 733 \\
\hline Densidade do solo & $\mathrm{kg} \mathrm{dm}^{-3}$ & 1,80 & 1,76 \\
\hline
\end{tabular}


Após subsolagem e gradagem do solo, fez-se a adubação com superfosfato simples, à base de $300 \mathrm{~kg} \mathrm{ha}^{-1}$, em sulco. A cultura semeada foi o melão (Cucumis melo L. híbrido Gold mine), com espaçamento entre fileiras de $2,0 \mathrm{~m}$ e $0,6 \mathrm{~m}$ entre covas e duas plantas por cova distanciadas $15 \mathrm{~cm}$. Depois da colheita e limpeza da área, foi realizada uma escarificação superficial manual com enxada, seguida do segundo plantio. O experimento constou de 36 parcelas de $36 \mathrm{~m}^{2}$, formadas por três fileiras de $6 \mathrm{~m}$, no total de 60 plantas por parcela.

Os tratamentos consistiram da combinação de dois métodos de medida do fator de cobertura do solo pela planta, duas águas de salinidades diferentes, sendo uma de origem arenítica $\left(\mathrm{CE}=0,55 \mathrm{dS} \mathrm{m}^{-1}\right)$ e a outra calcária $\left(\mathrm{CE}=2,65 \mathrm{dS} \mathrm{m}^{-1}\right)$ cujas análises químicas são apresentadas na Tabela 2, e seis lâminas de irrigação: $\mathrm{L}_{1}=0,55 \mathrm{ETm}, \mathrm{L}_{2}=0,70 \mathrm{ETm}, \mathrm{L}_{3}=0,85 \mathrm{ETm}, \mathrm{L}_{4}=1,00 \mathrm{ETm}$, $\mathrm{L}_{5}=1,15 \mathrm{ETm}$ e $\mathrm{L}_{6}=1,30 \mathrm{ETm}$, correspondendo a lâminas de irrigação de 201, 256, 311, 366, 421 e $476 \mathrm{~mm}$ no primeiro experimento e a 146, 186, 226, 266, 306 e $346 \mathrm{~mm}$ no segundo, para um período de 70 dias. No $1^{\circ}$ experimento, entre o $38^{\circ}$ e o $48^{\circ}$ dia, todas as lâminas de irrigação em estudo foram aplicadas em dobro, em virtude de falha no cálculo da lâmina.

Tabela 2. Análises químicas das águas usadas no experimento

\begin{tabular}{lccc}
\hline Características & Unidade & \multicolumn{2}{c}{ Origem da Água } \\
\cline { 3 - 4 } & & Calcária & Arenítica \\
\hline $\mathrm{CE}$ & $\mathrm{dS} \mathrm{m}{ }^{-1}$ & 2,65 & 0,55 \\
$\mathrm{pH}$ & - & 7,00 & 7,80 \\
$\mathrm{ISL}{ }^{*}$ & - & 0,25 & 0,35 \\
$\mathrm{Ca}$ & $\mathrm{mmol}_{\mathrm{c}} \mathrm{L}^{-1}$ & 11,90 & 3,10 \\
$\mathrm{Mg}$ & $\mathrm{mmol}_{\mathrm{c}} \mathrm{L}^{-1}$ & 6,20 & 1,20 \\
$\mathrm{~K}$ & $\mathrm{mmol}_{\mathrm{c}} \mathrm{L}^{-1}$ & 0,11 & 0,61 \\
$\mathrm{Na}$ & $\mathrm{mmol}_{\mathrm{c}} \mathrm{L}^{-1}$ & 8,16 & 0,91 \\
$\mathrm{Cl}$ & $\mathrm{mmol}_{\mathrm{c}} \mathrm{L}^{-1}$ & 17,60 & 1,40 \\
$\mathrm{HCO}$ & $\mathrm{mmol}_{\mathrm{c}} \mathrm{L}^{-1}$ & 6,80 & 3,20 \\
$\mathrm{CO}_{3}$ & $\mathrm{mmol}_{\mathrm{c}} \mathrm{L}^{-1}$ & 0,00 & 0,40 \\
\hline
\end{tabular}

* Índice de saturação de Langelier

A ETm da cultura foi estimada utilizando-se a metodologia recomendada por Allen et al. (1996) ou seja, o ETo por PenmanManteith e os valores do Kc revisados pela FAO; além disso, introduziram-se modificações, conforme Hernandez (1995) que consistem em corrigir a ETc, de acordo com a cobertura do solo pela cultura, através de medições a cada 3 dias do comprimento da rama total, no sentido transversal à fileira.

Nos estágios iniciais dos experimentos foram realizadas irrigações iguais para todos os tratamentos, de modo a assegurar a uniformidade de germinação. Depois de 10 dias da emergência completa das plantas, iniciou-se a diferenciação das lâminas por meio de sistema de irrigação por gotejamento, usando-se emissores de 3,75 $\mathrm{L} \mathrm{h}^{-1}$ distanciados $0,60 \mathrm{~m}$ na linha, monitorando-se a umidade do solo através de baterias de tensiômetros nas profundidades de $15,30,45$ e $55 \mathrm{~cm}$.

Para se avaliar o coeficiente de cobertura do solo, utilizaram-se os seguintes instrumentos: peça de madeira (Figura 1) que possui uma barra inferior e outra superior, cada uma com 20 orifícios de diâmetro 3 e $2 \mathrm{~mm}$, respectivamente, espaçados $10 \mathrm{~cm}$, onde foram efetuadas as visadas das plantas - método de Stocking, e uma régua milimetrada. Nos dois métodos, as leituras foram realizadas aleatoriamente, ao longo das linhas centrais das parcelas, sendo no primeiro experimento aos 21,33, 42 e 50 dias após o plantio e no segundo aos 20, 28, 34, 41, 51 e 62 dias. Em cada parcela e em cada época de medida, foram realizadas medições em 10 e 5 posições, usando-se a peça de madeira e a régua, respectivamente.

(A)

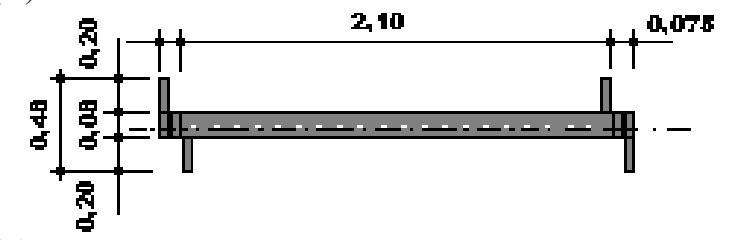

(B)

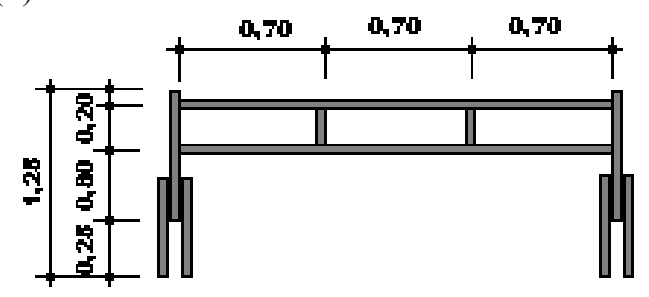

(C)

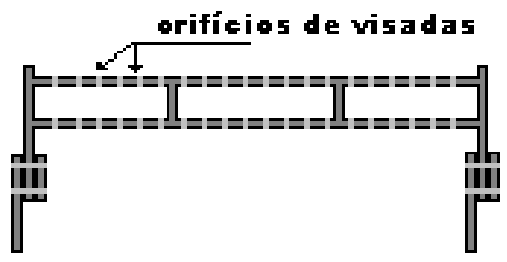

Figura 1. Medidor de Stocking: (A) vista superior, (B) vista lateral e $(\mathrm{C})$ corte longitudinal (valores em $\mathrm{m}$ )

No caso da régua, o cálculo do fator de cobertura foi obtido através das seguintes equações:

$\mathrm{FC}=0,01309 \mathrm{D}^{2}$, para $\mathrm{D}<19,1 \mathrm{~cm}$

$\mathrm{FC}=0,006545 \mathrm{D}^{2}+0,125 \mathrm{D}$, para $19,1 \mathrm{~cm} \leq \mathrm{D}<57,3 \mathrm{~cm}$

$\mathrm{FC}=0,5 \mathrm{D}$; para $\mathrm{D} \geq 57,3 \mathrm{~cm}$

em que

FC - fator de cobertura, em \%

D - diâmetro da copa da planta ou da faixa coberta pela cultura, em cm.

Os coeficientes nas equações acima foram deduzidos assumindo-se que as plantas na cova formavam uma subfaixa contínua, quando o diâmetro atingia $125 \%$ do espaçamento das duas plantas, e uma faixa total contínua, quando as plantas vizinhas entre covas apresentavam diâmetro $125 \%$ do espaçamento entre as mesmas. Com a peça de madeira, o fator foi obtido pela razão entre o somatório das visadas com vegetação e o valor total das visadas possíveis. Quando o campo de visada ficava parcialmente tomado pela planta, considerava-se meia visada.

Realizou-se análise de variância para cada época de amostragem, tanto para o $1^{\circ}$ como para o $2^{\circ}$ experimento, considerando-se os fatores método de medição, água de irrigação e lâmina, arranjado no esquema fatorial 2 × 2 × 6 , no delineamento em blocos inteiramente ao acaso, com três repetições. Para se estudar o efeito do tempo associado aos outros fatores, realizou-se análise multivariada para dados repetidos (Lima, 1996).

\section{RESULTADOS E DISCUSSÃO}

No resultado da análise multivariada apresentado na Tabela 3, verifica-se efeito significativo $(p<0,05$ e $p<0,01)$ das interações simples do tempo com lâmina de irrigação, método 
Tabela 3. Análise multivariável do fator de cobertura do solo nos primeiro e segundo experimentos

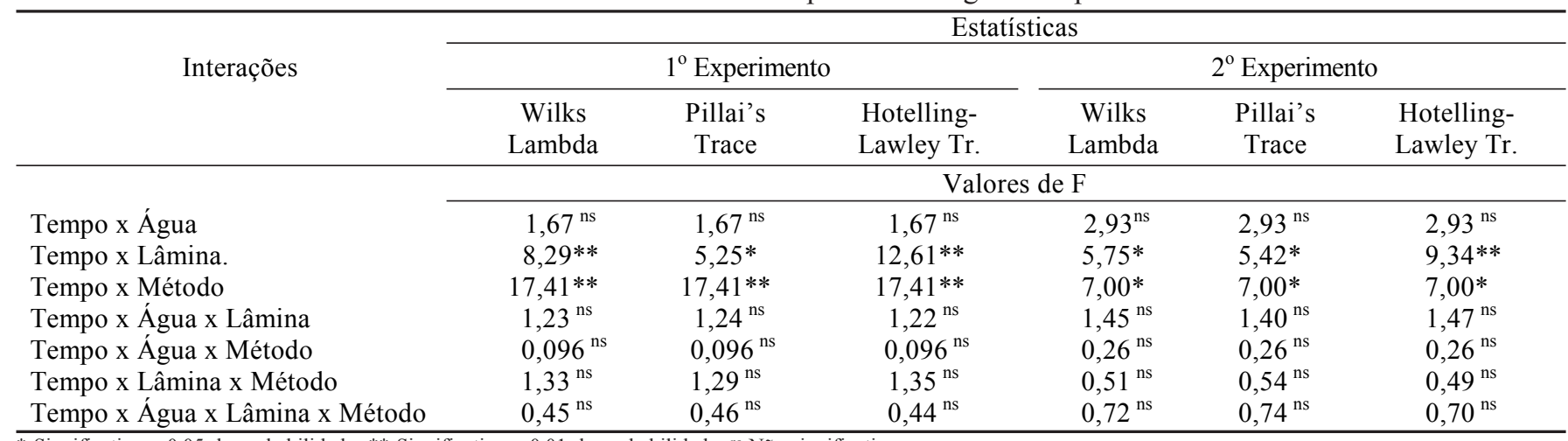

* Significativo a 0,05 de probabilidade; ** Significativo a 0,01 de probabilidade; ${ }^{\text {ns }}$ Não significativo

Tabela 4. Valores médios ${ }^{1}$ do fator de cobertura do solo (\%) em função de lâminas de irrigação e salinidade da água, determinados por duas metodologias, nos dois experimentos

\begin{tabular}{|c|c|c|c|c|c|c|c|c|c|c|}
\hline \multirow[t]{3}{*}{ Tratamentos $^{2}$} & \multicolumn{10}{|c|}{ Dias Após a Semeadura } \\
\hline & \multicolumn{4}{|c|}{$1^{\circ}$ Experimento } & \multicolumn{6}{|c|}{$2^{\circ}$ Experimento } \\
\hline & 21 & 33 & 42 & 50 & 20 & 28 & 34 & 41 & 51 & 62 \\
\hline $\mathrm{M}_{1}$ & $9,9 \mathrm{a}$ & $57,2 \mathrm{~b}$ & $93,7 \mathrm{a}$ & $97,9 \mathrm{a}$ & $6,7 \mathrm{a}$ & $21,6 \mathrm{~b}$ & $60,0 \mathrm{~b}$ & $78,8 \mathrm{~b}$ & $91,2 \mathrm{a}$ & $96,0 \mathrm{a}$ \\
\hline $\mathrm{M}_{2}$ & $8,4 \mathrm{~b}$ & $64,5 \mathrm{a}$ & $94,1 \mathrm{a}$ & $98,1 \mathrm{a}$ & $5,8 \mathrm{~b}$ & $25,7 \mathrm{a}$ & $66,3 \mathrm{a}$ & $83,1 \mathrm{a}$ & $91,0 \mathrm{a}$ & $95,1 \mathrm{a}$ \\
\hline \multicolumn{11}{|l|}{ Águas } \\
\hline \multicolumn{11}{|l|}{ Lâminas } \\
\hline $\mathrm{L}_{1}$ & 9,6 & 59,3 & 84,3 & 88,4 & 5,9 & 20,6 & 57,0 & 72,3 & 77,9 & 83,3 \\
\hline $\mathrm{L}_{2}$ & 8,8 & 58,4 & 93,8 & 100,0 & 6,6 & 24,0 & 60,2 & 71,6 & 80,2 & 91,1 \\
\hline $\mathrm{L}_{3}$ & 8,9 & 61,2 & 83,4 & 100,0 & 6,4 & 24,0 & 63,2 & 83,5 & 93,6 & 100,0 \\
\hline $\mathrm{L}_{4}$ & 9,6 & 59,4 & 95,2 & 100,0 & 6,2 & 23,0 & 63,4 & 82,5 & 97,1 & 99,0 \\
\hline $\mathrm{L}_{5}$ & 8,9 & 62,5 & 98,9 & 100,0 & 6,2 & 25,4 & 68,2 & 86,4 & 98,6 & 100,0 \\
\hline
\end{tabular}

${ }^{1}$ Médias seguidas pela mesma letra nas colunas não diferem significativamente a nível de $5 \%$, pelo teste t ou de Tukey

${ }^{2} \mathrm{~A}_{1}=$ Água com $\mathrm{CE}=0,55 \mathrm{dS} \mathrm{m}{ }^{-1} ; \mathrm{A}_{2}=$ Água com $\mathrm{CE}=2,65 \mathrm{dS} \mathrm{m}^{-1} ; \mathrm{M}_{1}=$ Método de Stocking; $\mathrm{M}_{2}=$ Método da régua

n.s. $=$ regressão não significativa

de medição e nível de salinidade da água de irrigação, indicando que existe comportamento diferenciado das curvas entre os níveis de cada fator estudado em função do tempo; no entanto, não houve efeito significativo $(p>0,05)$ entre as interações duplas desses fatores com o tempo. Morrison (1990) e Lima (1996) sugerem que se proceda a uma análise estatística univariada dos dados para os casos em que houver interação significativa, com o objetivo de se verificar o efeito de cada um dos fatores estudados em cada época de coleta de dados.

$\mathrm{Na}$ análise univariada observou-se efeito significativo ( $\mathrm{p}<0,05$ e $\mathrm{p}<0,01)$ do método de medição nas primeiras avaliações efetuadas em cada experimento (até 33 e 41 dias, respectivamente); por outro lado, o nível de salinidade da agua de irrigação afetou significativamente apenas no segundo experimento e a partir do $28^{\circ}$ dia após a semeadura. Com relação à lâmina de irrigação, no $1^{\circ}$ ciclo houve efeito linear, quadrático e cúbico significativo aos $33^{\circ}, 42^{\circ}$ e $50^{\circ}$ dias após a semeadura, respectivamente, enquanto no $2^{\circ}$ ciclo o efeito foi linear para os $28^{\circ}, 34^{\circ}$ e $41^{\circ}$ dias e quadrático para os $51^{\circ}$ e $62^{\circ}$ dias após a semeadura, não sendo significativa apenas para o início do primeiro ciclo. Os valores médios para cada época de medida encontram-se na Tabela 4.

Com respeito ao comportamento da cultura em relação a salinidade da água estudada no $1^{\circ}$ experimento, explica-se, primeiro, o fato da salinidade do solo ser inicialmente baixa e de ter crescido ao longo do cultivo, chegando a valores relativamente elevados no final deste ciclo; segundo, pela maior fração de lixiviação neste experimento com relação ao ensaio subseqüente.

No $2^{\circ}$ experimento verifica-se, através da Figura 2 , a diferença das curvas, indicando que as plantas cresceram menos quando foram irrigadas com a água de $\mathrm{CE}=2,65 \mathrm{dS} \mathrm{m}^{-1}$ devido, provavelmente, ao acúmulo de sais incorporados ao solo durante o $1^{\circ}$ experimento, seguido da adição de mais sais durante o $2^{\circ}$ ciclo. Brito (1997) testou vários níveis de salinidade na água de

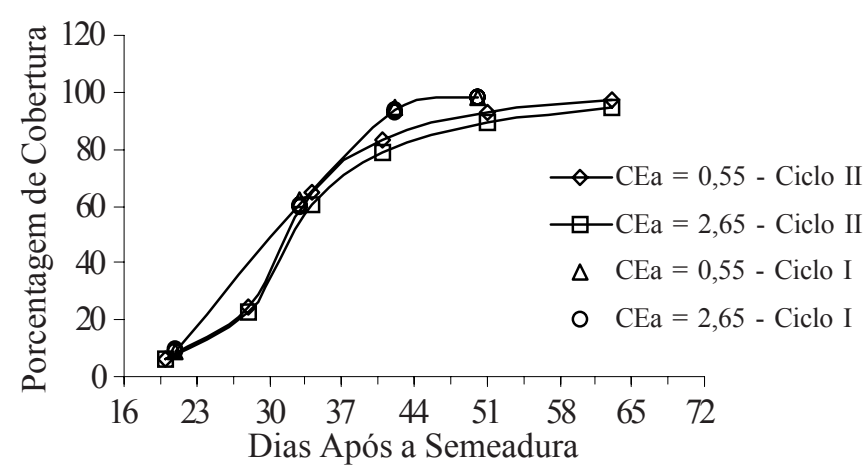

Figura 2. Comportamento do fator de cobertura sob diferentes níveis de salinidade da água de irrigação, em ambos os ciclos 
irrigação em melão e observou que somente a partir de $3,0 \mathrm{dS} \mathrm{m}^{-1}$ o desenvolvimento da cultura foi afetado significativamente.

Quanto às metodologias usadas nas medições do fator de cobertura do solo, a Tabela 4 revela que são diferentes, principalmente até $\mathrm{o} 42^{\circ}$ dia após a semeadura, quando as plantas estão perto de atingir o coeficiente máximo, o que pode ser melhor observado na Figura 3. Provavelmente, o método proposto por Stocking, principalmente enquanto a cultura não cobre uma faixa contínua de solo, avalia melhor o crescimento da planta, tendo em vista este método levantar informações de forma contínua, ao longo da fileira.

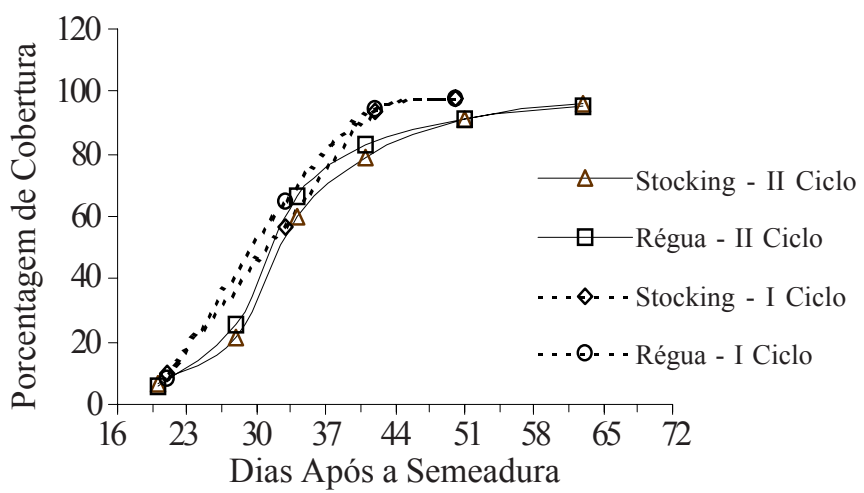

Figura 3. Comportamento do fator de cobertura em relação às metodologias de medições utilizadas durante o estudado

Os valores do coeficiente de cobertura do solo obtidos no estudo (Tabela 4 e Figura 3) mostram que o crescimento das plantas foi mais intenso no período de 28 a 42 dias após a semeadura, atingindo o coeficiente máximo nos $42^{\circ}$ e $51^{\circ}$ dias nos $1^{\circ}$ e $2^{\circ}$ experimentos, respectivamente, confirmando resultados obtidos por Bezerra (1995); no entanto, o maior crescimento das plantas evidenciado no $1^{\circ}$ experimento, foi favorecido pela maior disponibilidade de água no solo, haja visto que entre os $38^{\circ}$ e $48^{\circ}$ dias após a semeadura as lâminas de irrigação aplicadas foram o dobro das estabelecidas a priori, determinando maior absorção de água e nutrientes e, provavelmente, devido ao solo se encontrar, antes do primeiro cultivo, em repouso e ter recebido todas as etapas de preparo, além da salinidade média do solo ter sido, no primeiro ciclo, menor que no segundo.

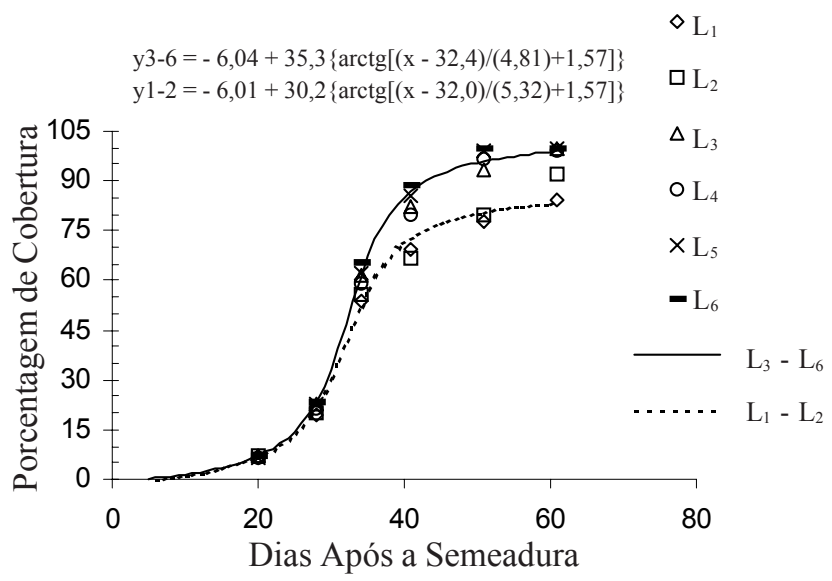

Figura 4. Comportamento do coeficiente de cobertura do solo ao longo do ciclo cultural, quando submetido a condições diferenciadas de lâminas no $2^{\circ}$ experimento
As equações do crescimento do fator de cobertura obtidas para o $2^{\circ}$ experimento usando-se a metodologia de Stocking para a diferentes lâminas de irrigação, são apresentadas na Figura 4, na qual observa-se que o aumento das lâminas induziu ao maior crescimento e que as lâminas $\mathrm{L}_{1}$ e $\mathrm{L}_{2}$ reduziram significativamente o desenvolvimento das plantas, sobretudo a partir dos 30 dias após o plantio. Verifica-se, ainda, elevado coeficiente de determinação $\left(r^{2}=0,999\right.$ para $\mathrm{L}_{3}$ a $\mathrm{L}_{6}$ e $\mathrm{r}^{2}=0,992$ para $\mathrm{L}_{1}-\mathrm{L}_{3}$ ) e entre os modelos que se ajustaram, um modelo arcotangente foi um deles.

\section{CONCLUSÕES}

Os métodos de medida do fator de cobertura do solo mostraram-se eficientes, detectando-se, em ambos, diferenças significativas entre os efeitos da qualidade da água e da lâmina de irrigação no desenvolvimento do melão. Os resultados obtidos pelo método da régua diferiram do método de Stocking na fase inicial e de crescimento do melão. A maior taxa de crescimento das plantas ocorreu entre os $28^{\circ} \mathrm{e} 42^{\circ}$ dias após a semeadura, sendo a equação do tipo arcotangente uma das que melhor se ajustaram para explicar o crescimento do fator de cobertura com o tempo.

\section{AGRADECIMENTOS}

Os autores agradecem à Fazenda São João Ltda, pelo apoio total na realização da pesquisa, financiando os equipamentos de irrigação, insumos e mão-de-obra.

\section{REFERÊNCIAS BIBLIOGRÁFICAS}

ABREU, T.A.; OLITTA, A.F.L.; MARCHETTI, D.A. Comparação de métodos de irrigação por sulco e por gotejo na cultura do melão, no Vale do São Francisco. Pesquisa Agropecuária Brasileira, Brasília, v.13, n.3, p.35-45, 1978.

ALLEN, R.G.; SMITH, M.; PEREIRA, L.S.; PRUIT, W.O. Proposed revision to the FAO: Procedure for estimating crop water requeriments. In: INTERNATIONAL SYMPOSIUM ON IRRIGATION OF HORTICULTURAL CROPS, 2, 1996, Chania. Proceedings..., Leven: ISHS, 1996. p.17-49.

ARAGÃO JUNIOR, T.C.; MAGALHÃES, C.R.; SANTOS, C.S.V. Efeitos de níveis de umidade no solo em cultivares de melão (Cucumis melo L.). Fortaleza: EPACE, 1991. 16p. Boletim de pesquisa, 19

BEDUM, J.A.; HERNANDEZ, F.B.T.; SUZUKI, M.A.; JAVAREZ JÚNIOR, A.; BUZETTI, S. Efeito de lâminas de irrigação sobre os principais parâmetros produtivos do meloeiro na região de Ilha Solteira, SP. In: CONGRESSO BRASILEIRO DE ENGENHARIA AGRÍCOLA, 22, 1993, Ilhéus. Anais... Ilhéus: SBEA/CEPLAC, 1993. v.4, p.2390-2400.

BEZERRA, J.W.T. Estimativa do coeficiente de cobertura para a cultura do melão no município de Mossoró, RN. Mossoró: ESAM, 1995, 34p. Monografia de Graduação 
BRITO, G.N.S. Produtividade do melão irrigado por gotejamento com água de diferentes níveis salinos. Fortaleza: UFC, 1997, 87p. Dissertação Mestrado

GOMES, H.P. Engenharia de irrigação: Hidráulica dos sistemas pressurizados, aspersão e gotejamento. João Pessoa: Ed. Universitária, UFPB, 1994. Cap. 4, p.177-228.

HERNÁNDEZ ABREU, J.M. Algunas consideraciones sobre el volumen de suelo mojado y su importancia en el diseño y eficiencia de sistemas de riego localizado. In: SEMINÁRIO LATINOAMERICANO SOBRERIEGO POR GOTEO, 3, 1979, Anais... Brasília: IICA, p.296-308.

HERNANDEZ, F.B.T. Efeito da supressão hídrica nos aspectos produtivos e qualitativos da cultura do melão. Piracicaba: ESALQ, USP, 1995. 90p. Tese Doutorado
KELLER, J.; BLIESNER, R.D. Sprinkle and trickle irrigation. New York: van Nostrand Reinhold, 1990. 652p.

LIMA, C.G. Análise de dados longitudinais proveniente de experimentos em blocos casualisados. Piracicaba: USP, 1996. 126p. Tese Doutorado

MORRISON, D.F. Multivariate statistical methods. 3. ed. New York: McGraw-Hill, 1990.414p

OLITTA, A. F. L . Os métodos de irrigação. São Paulo: Nobel, 1986.267p.

PIZARRO, F.C. Riegos localizados de alta frequencia: Goteo, microaspersión, exedación. 2. ed. Madrid: Mundi-Prensa, 1990.469p.

STOCKING, M. Modelagem de perdas de solo: Sugestões para uma aproximação brasileira. Porto Alegre: Secretaria Nacional de Produção Agropecuária, 1985. 92p. 